\title{
Miscibility and Hydrogen Bonding in Blends of Poly(vinylphenol-co-methyl methacrylate) with Poly(ethylene oxide)
}

\section{Shiao Wei Kuo and Feng Chih Chang*}

Institute of Applied Chemistry, National Chiao Tung University, Hsin Chu, Taiwan, Republic of China

Received J anuary 9, 2001; Revised Manuscript Received March 1, 2001

\begin{abstract}
Blends of poly(vinylphenol-co-methyl methacrylate) (PVPh-co-PMMA) with poly(ethylene oxide) (PEO) were prepared by solution casting from tetrahydrofuran (THF) solution. The miscibility behavior and hydrogen bonding of blends were investigated by differential scanning calorimetry (DSC), Fourier transform infrared spectroscopy (FTIR), and solid-state nuclear magnetic resonance (NMR). Experimental results indicate that PEO was miscible with PVPh-co-PMMA as shown by the existence of single composition-dependent glass transition temperatures over the entire composition range by DSC. In addition, a negative polymer-polymer interaction energy density "B" was calculated based on the melting depressi on of PEO using the Nishi-Wang equation. Solid-state N MR reveals single-exponential decay of proton spin-lattice relaxation times in the rotating frame $\left(\mathrm{T}_{1 \rho}{ }^{\mathrm{H}}\right)$ in the amorphous PVPh-coPMMA phase. Furthermore, FTIR and solid-state NMR results reveal that at least three competing equilibria are present in the blend; self-association of PVPh-co-PMMA copolymer (hydroxyl-hydroxyl and hydroxyl-carbonyl) and hydroxyl-ether interassociation between PVPh and PEO. Quantitative results show that although the hydroxyl-ether interassociation is favored at room temperature, the hydroxyl-carbonyl self-association dominates at higher temperatures ( $>70{ }^{\circ} \mathrm{C}$ ). The Painter-Coleman association model (PCAM) can predict three interacting functional groups based on our experimental results at various temperatures.
\end{abstract}

\section{Introduction}

The miscibility of polymer blends has received much attention in polymer science. Some of this research has been performed with blends in which one or two components are semicrystalline. A common component in crystalline miscible blends is a polyether, poly(ethylene oxide) (PEO), a highly crystalline polymer miscible with several amorphous polymers through hydrogen bonding. ${ }^{1-3}$ Various techniques have been adopted to determine the miscibility of polymer blends, including thermal analysis, ${ }^{4}$ dynamic mechanical analysis, ${ }^{5}$ small-angle X-ray scattering, ${ }^{6}$ microscopy $^{7}$ and solid-state NMR. ${ }^{8-13}$ Furthermore, DSC can determine whether one or two $T_{g}$ values and a single $T_{g}$ point is the most conventionally used criterion for the miscibility of a polymer blend. On the contrary, an immsicible polymer blend exhibits more than one $T_{g}$. A single compositionally dependent glass transition indicates full miscibility with a dimension on the order of $20-40 \mathrm{~nm}$. Over the years, various equations have been offered to predict the variation of the glass transition temperature of random copolymers or miscible blends as a function of composition, which can be well interpreted in terms of specific interaction within a polymer blend.

By Fourier transform infrared (FTIR) spectroscopy, the carbonyl, hydroxyl, and ether vibrations have been proved to be excellent clues to detect the molecular interaction. ${ }^{14-17}$ Solid state ${ }^{13} \mathrm{C}$ NMR is also a highly effective means of studying the miscibility and hydrogen bonding of polymer blends. The ${ }^{13} \mathrm{C}$ chemical shift and line shape in cross-polarization and magic angle spinning (CP/MAS) spectra can identify chemical environments of carbon in the blend, since the chemical shift

* To whom corresponding should be addressed. E-mail: changfc@cc.nctu.edu.tw. Telephone: 886-3-5712121 ext. 56502. Fax: 886-3-5723764 and the line shape are highly sensitive to the local electron density. If a specific interaction affects the local electron density, a change in chemical shift can be observed. This approach has been widely offered as evidence of the interaction between the blend components. The scale of miscibility of a polymer blend can be estimated from proton spin-lattice relaxation times in the rotating frame $\left(\mathrm{T}_{1 \rho}{ }^{\mathrm{H}}\right)$, measured by solid-state NMR.

In addition to studying the miscibility of PVPh-coPMMA with PEO blends by DSC and solid-state NMR, this study provides evidence of specific intermolecular association and self-association by using FTIR and solidstate NMR. The fraction of hydrogen bonding of the carbonyl group in the PVPh-co-PMMA/PEO blend is also calculated at various temperatures, as compared with the inter and self-association equilibrium constants of the Painter-Coleman association model ${ }^{18}$ (PCAM). Experimental data are obtained using the PCAM results to predict successfully the fraction carbonyl group that are hydrogen bonded.

\section{Experiment}

Samples. The polymers used in this study, poly(vinylphe nol-co-methyl methacrylate) (PVPh-co-PMMA) with VPh contents of $51 \mathrm{~mol} \%$, and poly(ethylene oxide) (PEO) with $\mathrm{M}_{\mathrm{n}}=$ 20000 were obtained from Aldrich Co. Figure 1 illustrates the chemical structures of (PVPh-co-PMMA) and PEO.

Blend Preparations. Blends of various (PVPh-co-PMMA)/ PEO compositions were prepared by solution casting. Tetrahydrofuran solutions containing a 5 wt \% polymer mixture were stirred for 6-8 $\mathrm{h}$ and cast on a Teflon dish. The solution was allowed to evaporate slowly at room temperature for 1 day. The blend films were then dried at $50{ }^{\circ} \mathrm{C}$ for 2 days.

Characterizations. Differential Scanning Calorimetry. $\mathrm{T}_{\mathrm{g}} \mathrm{S}$ of blend films were determined by a DSC with a DuPont (DSC-9000), with a scan rate of $20{ }^{\circ} \mathrm{C} / \mathrm{min}$ over a temperature range of $30-150^{\circ} \mathrm{C}$. The measurement was made using a 5-10 mg sample on a DSC sample cell after the sample 


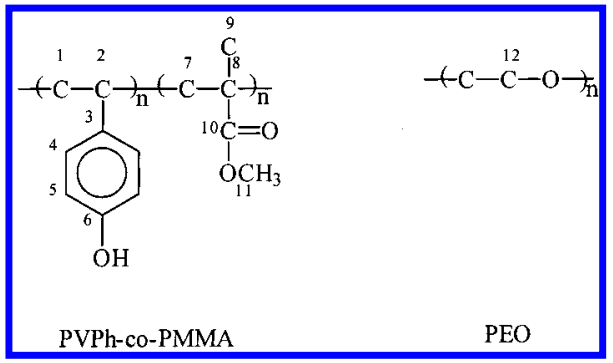

Figure 1. Chemical structures of PVPh-co-PMMA and PEO and their atom numbering schemes

was quickly cooled to $-100^{\circ} \mathrm{C}$ from the melt of the first scan. The glass transition temperature is taken as the midpoint of the heat capacity transition between the upper and lower points of deviation from the extrapolated liquid and glass lines. The isothermal crystallization from the melt was also examined by DSC. The samples were melted at $80{ }^{\circ} \mathrm{C}$ for $10 \mathrm{~min}$, cooled quickly to the crystallization temperature $\left(T_{c}\right)$, and then maintained at $T_{c}$ for $12 \mathrm{~h}$. After isothermal crystallization was complete, the samples were cool ed at $0{ }^{\circ} \mathrm{C}$ and heated to 100 ${ }^{\circ} \mathrm{C}$ at a rate of $10^{\circ} \mathrm{C} / \mathrm{min}$ to measure the mel ting temperature $\left(T_{m}\right)$.

Infrared Spectroscopy. I nfrared spectra of polymer blend films were determined by using the conventional $\mathrm{NaCl}$ dish method. The THF solution containing the blend was cast onto a $\mathrm{NaCl}$ disk and dried under conditions similar to those used in the bulk preparation. The film used in this study was thin enough to obey the Beer-Lambert law. FTIR measurements were recorded on a Nicolet Avatar $320 \mathrm{FT}$-IR spectrophotometer, and 32 scans were collected with a spectral resolution of $1 \mathrm{~cm}^{-1}$. Owing to that fact that the sample containing hydroxyl groups is water sensitive, a pure nitrogen flow was used to purge the IR optical box in order to maintain dry sample films. IR spectra recorded at elevated temperatures were obtained by using a cell mounted inside the temperature-controlled compartment of the spectrometer.

Solid State NMR. High-resolution solid state ${ }^{13} \mathrm{C}$ NMR experiments were carried out at room temperature using a Bruker DSX-400 spectrometer operating at resonance frequencies of 399.53 and $100.47 \mathrm{MHz}$ for ${ }^{1} \mathrm{H}$ and ${ }^{13} \mathrm{C}$, respectively. The ${ }^{13} \mathrm{C}$ CP/MAS spectra were measured with a $3.9 \mu \mathrm{s} 90^{\circ}$ pulse, with $3 \mathrm{~s}$ pulse delay time, acquisition time of $30 \mathrm{~ms}$, and 2048 scans were accumulated. All NMR spectra were taken at $300 \mathrm{~K}$ using broad band proton decoupling and a normal cross-polarization pulse sequence. A magic angle sample spinning (MAS) rate of $5.4 \mathrm{kHz}$ was used to eliminate resonance broadening due to the anisotropy of chemical shift tensors. The proton spin-lattice relaxation time in the rotating frame $\left(\mathrm{T}_{1 \rho}{ }^{\mathrm{H}}\right)$ was measured indirectly via carbon observation using a $90^{\circ}-\tau$-spin lock pulse sequence prior to cross-polarization. The data acquisition was performed via ${ }^{1} \mathrm{H}$ decoupling and delay time $(\tau)$ ranging from 0.3 to $15 \mathrm{~ms}$ with a contact time of $1.0 \mathrm{~ms}$

\section{Results and Discussion}

Thermal Analyses. Differential scanning cal orimetry (DSC) is extensively used to investigate miscibility in polymer blends. A single compositionally dependent glass transition is an indication of full miscibility at a dimensional scale between 20 and $40 \mathrm{~nm}$. Single $\mathrm{T}_{9}$ behavior represents macroscopically and implies full miscibility of the blend. Figure 2 shows DSC analyses of the PVPh-co-PMMA/PEO blends of various compositions. The pure amorphous PVPh-co-PMMA exhibits one $\mathrm{T}_{\mathrm{g}}$ at $134.9^{\circ} \mathrm{C}$ while the $\mathrm{T}_{\mathrm{g}} \mathrm{S}$ of PVPh-co-PMMA shift to lower temperatures as the PEO content in the blend increases. F urthermore, the melting temperature of the PEO component in the blend decreases with the increase of the PVPh-co-PMMA content. Table 1 summarizes the thermal properties of PVPh-co-PMMA,

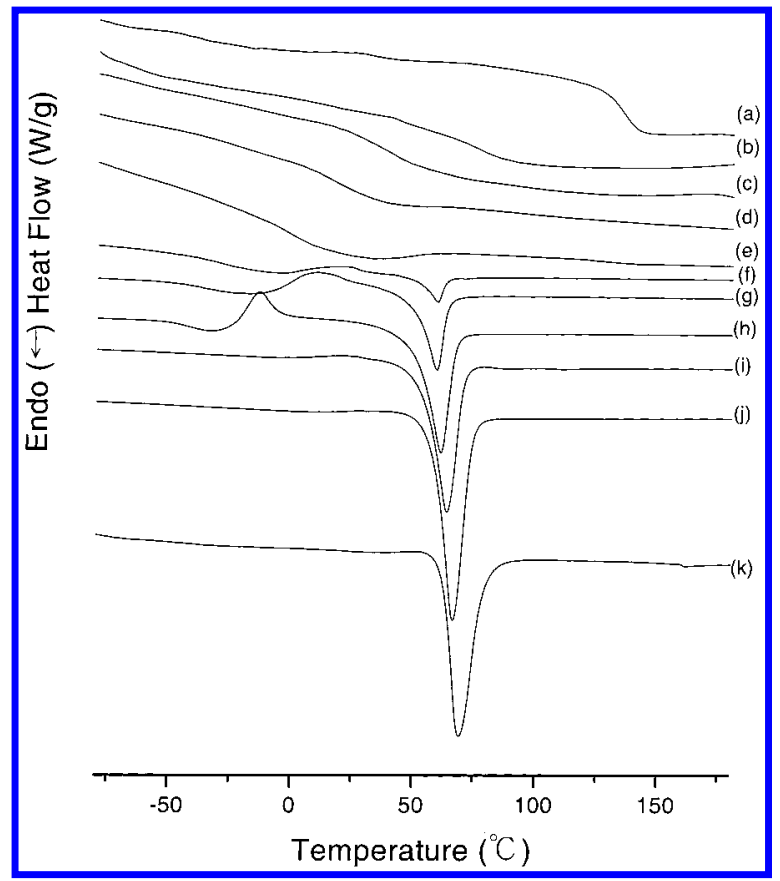

Figure 2. DSC scans of PVPh-Co-PMMA/PEO blends with different compositions: (a) 100/0; (b) 90/10; (c) 80/20; (d) 70/ 30; (e) 60/40; (f) 50/50; (g) 40/60; (h) 30/70; (i) 20/80; (j) 10/90; (k) $0 / 100$

Table 1. Thermal Properties of PVPh-co-PMMA/PEO Blends

\begin{tabular}{crrrrr}
\hline $\begin{array}{c}\text { PVPh-co- } \\
\text { PMMA/PEO }\end{array}$ & \multicolumn{1}{c}{$\begin{array}{c}\mathrm{T}_{\mathrm{g}} \\
\left({ }^{\circ} \mathrm{C}\right)\end{array}$} & $\begin{array}{c}\mathrm{T}_{\mathrm{m}} \\
\left({ }^{\circ} \mathrm{C}\right)\end{array}$ & $\begin{array}{c}\Delta \mathrm{H}_{\mathrm{f}} \\
(\mathrm{J} / \mathrm{g})\end{array}$ & $\begin{array}{c}\mathrm{T}_{\mathrm{c}} \\
\left({ }^{\circ} \mathrm{C}\right)\end{array}$ & $\begin{array}{c}\Delta \mathrm{H}_{\mathrm{c}} \\
(\mathrm{J} / \mathrm{g})\end{array}$ \\
\hline $100 / 0$ & 134.9 & & & & \\
$90 / 10$ & 71.9 & & & & \\
$80 / 20$ & 42.2 & & & & \\
$70 / 30$ & 18.3 & & & & \\
$60 / 40$ & 2.7 & & & & \\
$50 / 50$ & -19.6 & 59.0 & 5.6 & 20.0 & -4.2 \\
$40 / 60$ & -32.7 & 59.0 & 44.7 & 10.5 & -30.4 \\
$30 / 70$ & -43.3 & 60.9 & 84.9 & -13.8 & -31.9 \\
$20 / 80$ & -32.9 & 63.6 & 104.0 & & \\
$10 / 90$ & -38.2 & 66.3 & 128.6 & & \\
$0 / 100$ & -67.0 & 69.2 & 175.7 & &
\end{tabular}

PEO, and their blends. All PVPh-co-PMMA/PEO blends show only a single glass transition temperature $\left(T_{g}\right)$ over the entire blend composition. A single $\mathrm{T}_{\mathrm{g}}$ strongly suggests that these are fully miscible blends with a homogeneous amorphous phase.

Various equations have been offered to predict the variation of the glass transition temperature of a random copolymer or miscible blend as a function of composition. The dependence of $\mathrm{T}_{\mathrm{g}}$ on the composition of the miscible PVPh-co-PMMA/PEO blends is shown in Figure 3. The experimental $T_{g}$ vs composition curve is not well fit either with the Fox ${ }^{19}$ or the GordonTaylor equation. ${ }^{20}$ However, the K wei equation ${ }^{21}$ fits the experimental data well. The K wei equation is as follows

$$
T_{g}=\frac{W_{1} T_{g 1}+k W_{2} T_{g 2}}{W_{1}+k W_{2}}+q W_{1} W_{2}
$$

where $W_{1}$ and $W_{2}$ denote weight fractions of the compositions, $T_{g 1}$ and $T_{g 2}$ represent the corresponding blend component glass transition temperatures, and $\mathrm{k}$ and $\mathrm{q}$ are fitting constants. $\mathrm{k}=4$ and $\mathrm{q}=32$ are obtained from the nonlinear least-squares "best fit" values. Here q is a parameter corresponding to the strength of hydrogen 


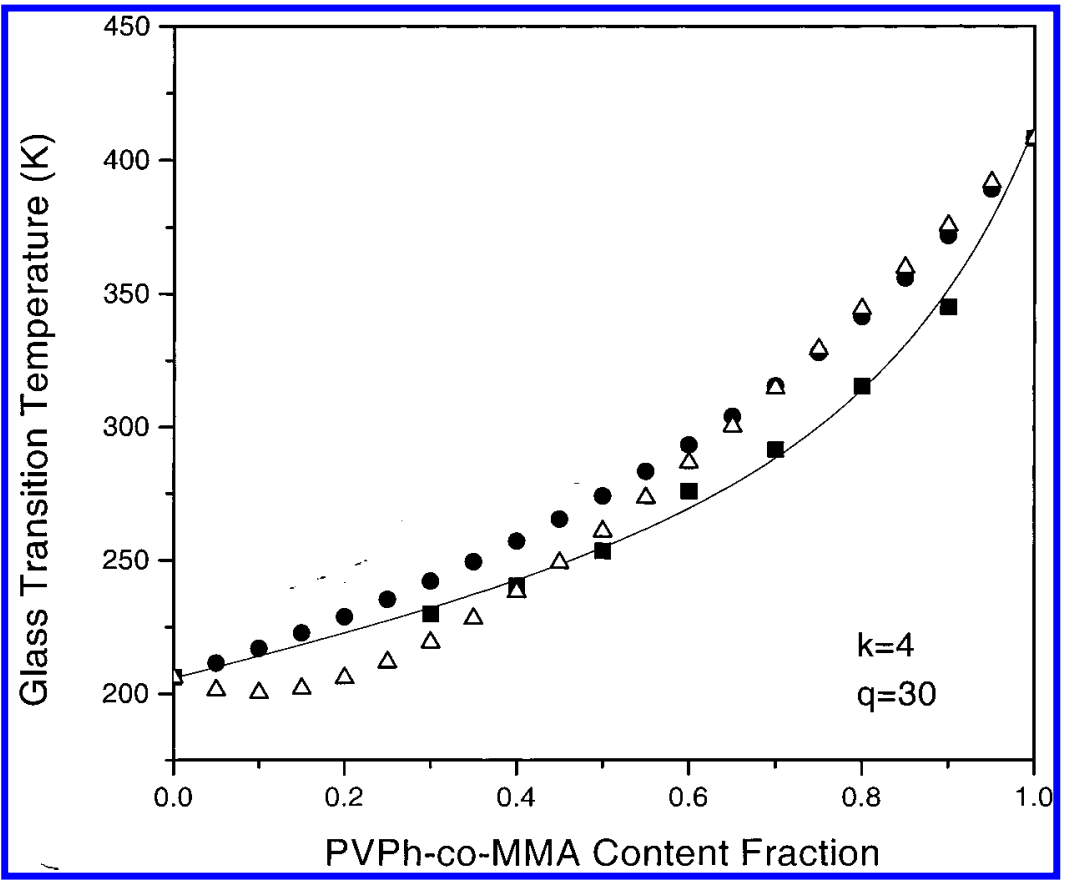

Figure 3. $T_{g}$ vs composition curves based on ( $\left.\mathbf{\square}\right)$ experimental data, $(\mathbf{\bullet})$ the F ox equation, $(\triangle)$ the Gordon-Taylor equation, and $(-)$ the Kwei equation.

bonding in the blend, which should be considered as a balance between the breaking of the self-association hydrogen bonding and the forming of the interassociation. The value of $q$ depends on the change of entropy corresponding to the change in the number of hydrogen bonding interactions with the PEO in this blend. In this study, a positive $q$ of 30 was obtained, indicating a strong intermolecular interaction between PEO and PVPh-co-PMMA.

Equilibrium Melting Temperature and Melting Point Depression. The depression of the melting point of a crystalline polymer blended with an amorphous polymer provides important information about its miscibility and its associated polymer-polymer interaction parameter. The temperature reduction is caused by morphological effects and for thermodynamic reasons. From the thermodynamic consideration, thermodynamic properties of the crystalline component in the amorphous phase can be determined. When two polymers are miscible in the molten state, the chemical potential of the crystallizable polymer is decreased due to the addition of the second component. This fact leads to a reduction in the equilibrium melting temperature of the resulting blend. The data obtained in this study were analyzed by the Nishi-Wang equation ${ }^{22}$ based on the Flory-Huggins theory. ${ }^{23}$ The melting point depression is given by eq $2,22,23$ where $T_{m}{ }^{0}$ and $T_{m_{2}}{ }^{0}$ denote the

$$
\begin{array}{r}
\frac{1}{T_{m}{ }^{0}}-\frac{1}{T_{m_{2}}{ }^{0}}=\frac{-R}{\Delta H_{2 u}} \frac{V_{2 u}}{V_{1 u}}\left[\frac{\ln \phi_{2}}{x_{2}}+\left(\frac{1}{x_{2}}-\frac{1}{x_{1}}\right)\left(1-\phi_{2}\right)+\right. \\
\left.\chi_{12}\left(1-\phi_{2}\right)^{2}\right]
\end{array}
$$

equilibrium melting points of the pure crystallizable component and of the blend, respectively. $V_{2 u}$ and $V_{1 u}$ are the molar volumes of the repeating units of the polymers. $\mathrm{R}$ is the universal gas constant. $\Delta \mathrm{H}_{2 \mathrm{u}}$ is the heat of fusion of the perfectly crystall izable polymer per mole of repeat unit; subscript 1 represents the amorphous polymer, and subscript 2 the crystalline polymer. $x_{1}$ and $x_{2}$ are degrees of polymerization; $\Phi$ is the volume fraction of the component in the blend, and $\chi_{12}$ is the polymer-polymer interaction parameter. When both $x_{1}$ and $x_{2}$ are large, for high molecular weight polymers, these related terms in eq 2 can be neglected. The interaction parameter $\chi_{12}$ can be written as

$$
\chi_{12}=\frac{\mathrm{BV}_{1 \mathrm{u}}}{\mathrm{RT}}
$$

Substituting eq 3 into eq 2 yields the Nishi-Wang equation ${ }^{22}$

$$
\mathrm{T}_{\mathrm{m}}{ }^{0}-\mathrm{T}_{\mathrm{m}_{2}}{ }^{0}=-\mathrm{T}_{\mathrm{m}}{ }^{0} \frac{\mathrm{BV} \mathrm{V}_{2 \mathrm{u}}}{\Delta \mathrm{H}_{2 \mathrm{u}}} \phi_{1}^{2}
$$

where $\Delta \mathrm{H}_{2 \mathrm{u}} \mathrm{N}_{2 \mathrm{u}}$ is the latent heat of fusion of $100 \%$ crystalline component per unit volume and $\mathrm{B}$ denotes the interaction energy density between blend components.

The method of H offman and Weeks ${ }^{24}$ has been used to determine the equilibrium melting temperatures for pure PEO $\left(\mathrm{Tm}_{\mathrm{m}}{ }^{0}\right)$ and blends $\left(\mathrm{T}_{\mathrm{m}_{2}}{ }^{0}\right)$ of given compositions, to eliminate the morphological effect from the melting point depression. Figure 4 presents the HoffmanWeeks plots to obtain the equilibrium melting points for pure PEO and various PVPh-co-PMMA/PEO blends. The $\mathrm{T}_{\mathrm{m}_{2}}{ }^{0}$ values decrease with increasing PVPh-coPMMA content. An immsicible or partially miscible blend typically does not show the depression of the equilibrium melting point $\left(\mathrm{T}_{\mathrm{m}}{ }^{0}\right), \mathrm{T}_{\mathrm{m}_{2}}{ }^{0}$ is depressed significantly with increasing the content of the amorphous polymer for a miscible blend, especially one containing specific interaction between the components. As also shown in Figure 4, the melting point depression, $\Delta T_{m}$, for PVPh-Co-PM MA/PE O blends increases linearly with the volume fraction of the amorphous component $\left(\Phi_{1}\right)$. The weight fraction is converted into the volume fraction using the molar volume of monomeric units determined by a group contribution method. ${ }^{18} \mathrm{~A} B$ value of -29.23 is calculated from the slope of Figure 5 


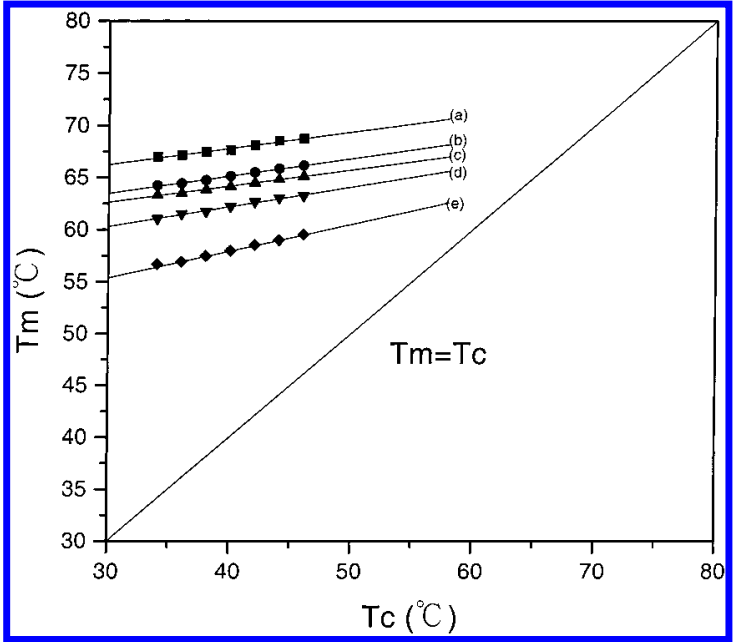

Figure 4. Hoffman-Weeks plots for PVPh-co-PMMA/PEO blends: (a) 0/100; (b) 10/90; (c) 20/80; (d) 30/70; (e) 40/60.

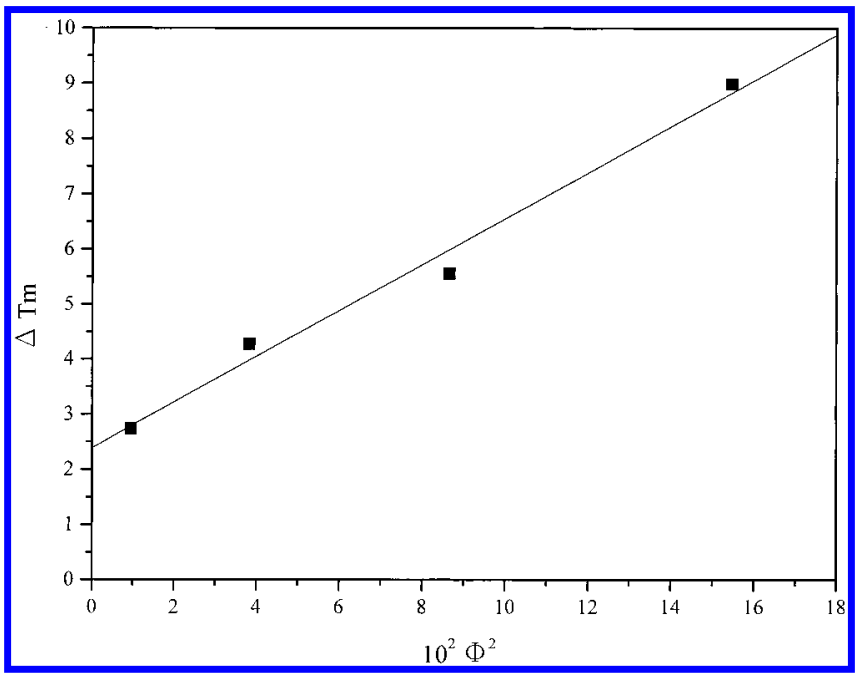

Figure 5. Plots of the equilibrium melting temperature depression vs the square of the volume of fraction of PVPhco-PMMA.

according to eq 4 and the data of $\mathrm{V}_{2 \mathrm{u}}=38.1 \mathrm{~cm}^{3} / \mathrm{mol}$ and $\Delta \mathrm{H}_{2 \mathrm{u}}=1980 \mathrm{cal} / \mathrm{mol}{ }^{25}$ The negative $\mathrm{B}$ value is consistent with a miscible system. According to eq 4, the intercept of a plot of $\Delta T_{m}$ vs $\Phi_{1}{ }^{2}$ should be close to zero. However, the line has a finite intercept because of the significant entropic effect of blending two polymers.

Fourier Transform Infrared Spectroscopy Analyses. I nfrared spectroscopy has been proven a highly effective means of investigating specific interactions between polymers. This tool can be used to study the mechanism of interpolymer miscibility through the formation of hydrogen bonding both qualitatively and quantitatively. Self-association may occur especially by hydroxyl-hydroxyl and hydroxyl-carbonyl hydrogen bonding, taking into account the chemical structure of PVPh-Co-PMMA. Figure 6 shows the infrared spectra of the carbonyl stretching measured at $25{ }^{\circ} \mathrm{C}$ ranging from 1660 to $1800 \mathrm{~cm}^{-1}$ for PVPh-Co-PMMA, PEO, and their blends. The carbonyl stretching for the pure PVPhco-PMMA is split into two bands, absorption by free and hydrogen-bonded carbonyl groups at 1730 and 1705 $\mathrm{cm}^{-1}$, respectively. These bands can be readily decomposed into two Gaussian peaks, with areas corresponding to the free carbonyl $\left(1730 \mathrm{~cm}^{-1}\right)$ and the hydrogen-

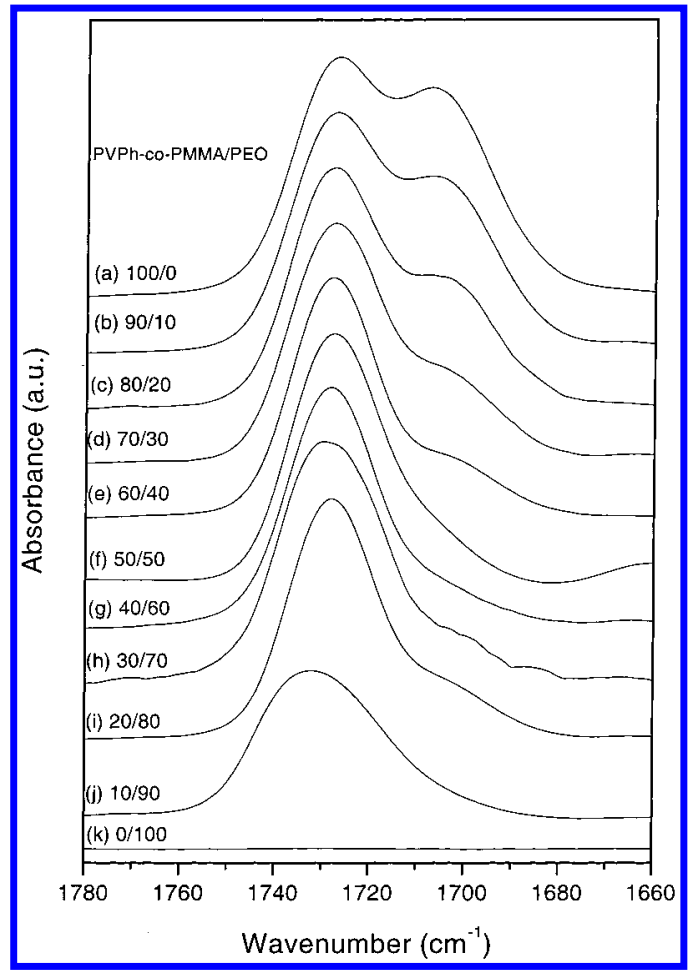

Figure 6. FTIR spectra recorded at room temperature in the $1660-1780 \mathrm{~cm}^{-1}$ region for PVPh-Co-PMMA/PEO blends: (a) 100/0; (b) 90/10; (c) 80/20; (d) 70/30; (e) 60/40; (f) 50/50; (g) 40/ 60; (h) 30/70; (i) 20/50; (j) 10/90; (k) 0/100.

Table 2. Curve-Fitting Results of the PVPh-co-PMMA/ PEO Blends at Room Temperature

\begin{tabular}{lcccccccc}
\hline & \multicolumn{3}{c}{ free $\mathrm{C}=\mathrm{O}$} & & \multicolumn{3}{c}{$\mathrm{H}$-bonded $\mathrm{C}=\mathrm{O}$} \\
\cline { 2 - 4 } $\begin{array}{c}\text { blend } \\
\text { (wt \%) }\end{array}$ & $\begin{array}{c}v \\
\left(\mathrm{~cm}^{-1}\right)\end{array}$ & $\begin{array}{c}\mathrm{W}_{1 / 2} \\
\left(\mathrm{~cm}^{-1}\right)\end{array}$ & $\begin{array}{c}\mathrm{A}_{\mathrm{f}} \\
(\%)\end{array}$ & $\begin{array}{c}v \\
\left(\mathrm{~cm}^{-1}\right)\end{array}$ & $\begin{array}{c}\mathrm{W}_{1 / 2} \\
\left(\mathrm{~cm}^{-1}\right)\end{array}$ & $\begin{array}{c}\mathrm{A}_{\mathrm{b}} \\
(\%)\end{array}$ & $\begin{array}{c}\mathrm{fb} \\
(\%)\end{array}$ \\
\hline $100 / 0$ & 1729.6 & 17.17 & 41.40 & & 1706.3 & 24.24 & 58.60 & 48.55 \\
$90 / 10$ & 1729.3 & 17.26 & 46.74 & & 1705.7 & 24.45 & 53.26 & 43.17 \\
$80 / 20$ & 1728.9 & 17.23 & 53.86 & & 1704.8 & 23.06 & 46.14 & 36.35 \\
$70 / 30$ & 1728.7 & 17.53 & 61.73 & & 1706.3 & 26.56 & 38.27 & 29.24 \\
$60 / 40$ & 1728.4 & 17.14 & 70.26 & & 1704.5 & 23.79 & 29.74 & 22.00 \\
$50 / 50$ & 1728.7 & 16.23 & 75.26 & & 1712.7 & 18.53 & 24.74 & 17.97 \\
$40 / 60$ & 1728.5 & 17.65 & 78.46 & & 1709.8 & 17.94 & 21.54 & 15.47 \\
$30 / 70$ & 1730.0 & 19.34 & 81.56 & & 1710.3 & 18.00 & 19.44 & 13.09 \\
$20 / 80$ & 1730.5 & 84.51 & 75.99 & & 1709.7 & 23.07 & 15.01 & 10.53 \\
$10 / 90$ & 1733.9 & 20.61 & 87.46 & & 1717.0 & 24.11 & 12.54 & 8.73
\end{tabular}

$* \mathrm{fb}$ : fraction of hydrogen bonding

bonded carbonyl (1705 $\mathrm{cm}^{-1}$ ) absorptions. Using the respective absor ptivity coefficients allows us to cal culate the fraction of these two carbonyl groups from the relative intensities of these two bands. The fraction of the hydrogen-bonded carbonyl group ${ }^{18}$ is calculated from eq 5 , where $A_{b}$ and $A_{f}$ are the peak areas corresponding

$$
f_{b}{ }^{C=O}=\frac{A_{b} / 1.5}{A_{b} / 1.5+A_{f}}
$$

to the hydrogen-bonded carbonyl and the free carbonyl groups, respectively. The conversion coefficient of 1.5 is the absorptivity ratio of these two bands, the "free" and "hydrogen-bonded" carbonyl groups, in an ester group. ${ }^{18}$ Table 2 summarizes the curve fitting results indicating that the fraction of hydrogen bonded carbonyl groups decreases as PEO content increases. As a result, the PMMA carbonyl competes with the ether oxygen of PEO to form a hydrogen bond with the hydroxyl group of the PVPh. According to the Painter-Coleman as- 
Table 3. Summary of the Self-Association and Interassociation Equilibrium Constants of PVPh-co-PMMA/PEO Blends

\begin{tabular}{|c|c|c|c|c|}
\hline & & & $\begin{array}{c}\text { equilib } \\
\text { const } \\
\mathrm{K}\left(25^{\circ} \mathrm{C}\right)\end{array}$ & $\begin{array}{c}\text { enthalpy, } \\
\Delta \mathrm{H} \\
\text { (kcal/mol) }\end{array}$ \\
\hline \multicolumn{3}{|c|}{$\begin{array}{l}\text { self-associationa } \\
\text { dimer formation } \mathrm{K}_{2} \\
\text { multimer formation } \mathrm{K}_{\mathrm{B}} \\
\text { between VPh and MMA K } \mathrm{K}_{\mathrm{C}} \\
\text { interassociation between }{ }^{\mathrm{b}} \\
\text { PVPh and PEO }\end{array}$} & $\begin{array}{l}21.0 \\
66.8 \\
67.4 \\
88.3\end{array}$ & $\begin{array}{l}-5.60 \\
-5.20 \\
-4.20 \\
-5.40\end{array}$ \\
\hline polymer & $\begin{array}{c}\text { molar } \\
\text { vol } \\
(\mathrm{mL} / \mathrm{mol})\end{array}$ & $\begin{array}{c}\mathrm{mol} \\
\mathrm{wt} \\
(\mathrm{g} / \mathrm{mol})\end{array}$ & $\begin{array}{l}\text { solubility } \\
\text { param } \\
(\mathrm{cal} / \mathrm{mL})^{0.5}\end{array}$ & $\begin{array}{c}\text { deg of } \\
\text { polymn, } \\
\text { DP }\end{array}$ \\
\hline $\begin{array}{l}\text { PVPhC } \\
\text { PMMAC }^{c} \\
\text { PEOC }^{c}\end{array}$ & $\begin{array}{r}100.00 \\
84.90 \\
38.10\end{array}$ & $\begin{array}{r}120.10 \\
100.12 \\
44.06\end{array}$ & $\begin{array}{r}10.60 \\
9.10 \\
9.40\end{array}$ & $\begin{array}{l}500 \\
500 \\
500\end{array}$ \\
\hline
\end{tabular}

a Reference 36. b Reference 37. c Estimated by using a group contribution method proposed by Coleman et al. ${ }^{18}$

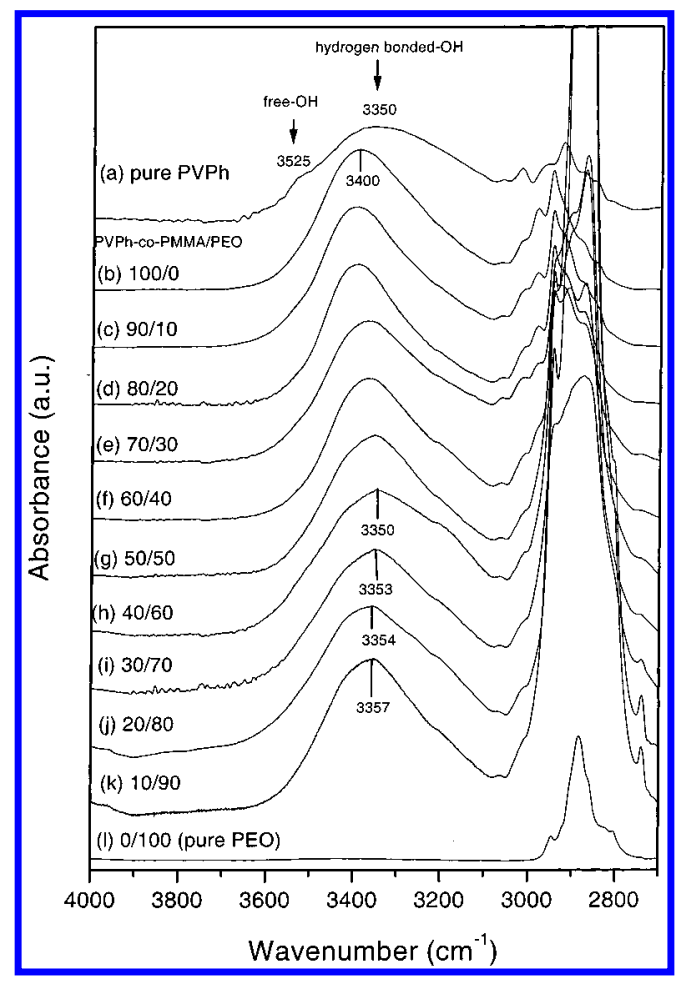

Figure 7. FTIR spectra recorded at room temperature in the $2700-4000 \mathrm{~cm}^{-1}$ region for pure PVPh and various PVPh-coPMMA/PEO blends: (a) pure PVPh; (b) 100/0; (c) 90/10; (d) 80/20; (e) 70/30; (f) 60/40; (g) 50/50; (h) 40/60; (i) 30/70; (j) 20/ 50; (k) 10/90; (I) 0/100.

sociation model (PCAM), Table 2 shows that the decrease in the fraction of hydrogen bonded carbonyl groups with increasing PEO content implies that the interassociation equilibrium constant of hydroxyl-ether has a larger value than the self-associations equilibrium constant of hydroxyl-carbonyl at room temperature. Table 3 lists all the parameters required by the PainterColeman association model to estimate thermodynamic properties for the PVPh-co-PMMA/PEO blend.

Figure 7 shows the absorption region of the pure PVPh, PVPh-co-PMMA, and various PVPh-co-PMMA/ PEO blends between 2700 and $4000 \mathrm{~cm}^{-1}$ at room temperature. As shown in Figure 7a, the pure PVPh polymer exhibits two bands in the hydroxy stretching region of the infrared spectrum. The free hydroxyl group

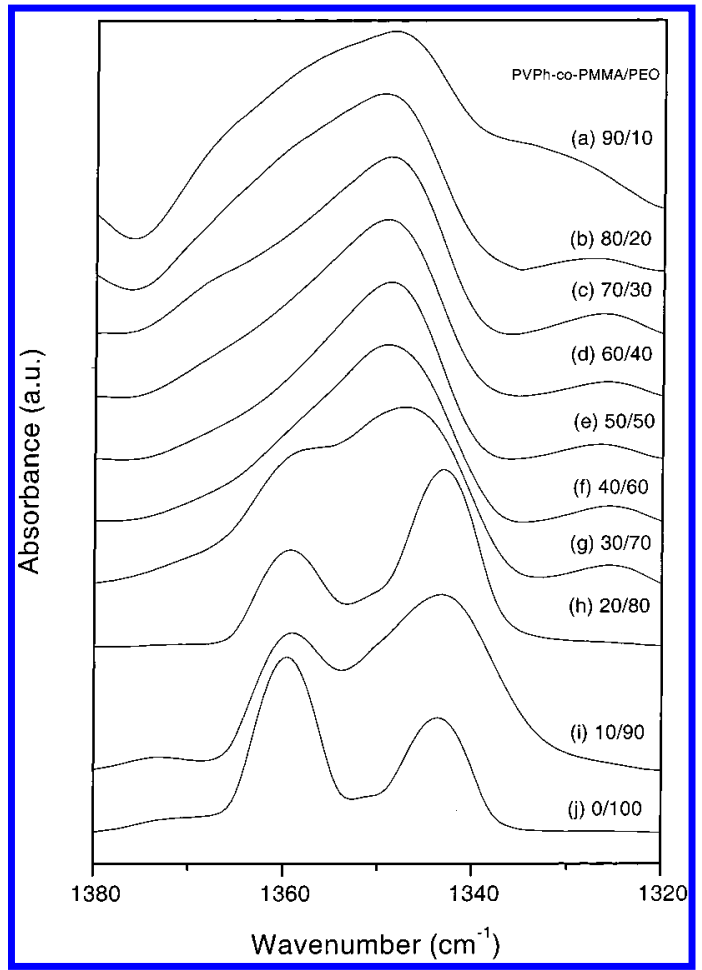

Figure 8. FTIR spectra recorded at room temperature at 1320 $\mathrm{cm}^{-1}-1380 \mathrm{~cm}^{-1}$ region for $\mathrm{PVPh}-\mathrm{Co}-\mathrm{PMMA}$ MEO blends: (a) 90/10; (b) 80/20; (c) 70/30; (d) 60/40; (e) 50/50; (f) 40/60; (g) 30/ 70; (h) 20/50; (i) 10/90; (j) 0/100.

absorption is located at $3525 \mathrm{~cm}^{-1}$, while the hydrogenbonded hydroxyl gives a broad absorption at $3350 \mathrm{~cm}^{-1}$ due to wide distribution of hydrogen-bonded hydroxyl groups. However, the pure PVPh-co-PMMA (Figure 7b) shows only one band at about $3400 \mathrm{~cm}^{-1}$ in the hydroxyl-stretching region of the infrared spectrum. This reflects the new distribution of hydrogen bonded be tween hydroxyl-hydroxyl and hydroxyl-carbonyl specific interactions. Furthermore, the band at $3400 \mathrm{~cm}^{-1}$ is shifted to $3350 \mathrm{~cm}^{-1}$, a lower wavenumber, for blends containing 60 wt \% PEO content (Figure 7g). This change is come from the switch from the intramolecular hydroxyl-carbonyl bond to the intermolecular hydroxylether bond, indicating that there is hydrogen-bonding interaction between the PEO ether group and the hydroxyl group of PVPh. The average strength of the intermolecular interaction can be obtained by the extent of frequency difference $(\Delta v)$ between the hydrogen bonded hydroxyl absorption and free hydroxyl absorption. A $\Delta v=175 \mathrm{~cm}^{-1}$ value for PVPh-co-PMMA/PEO $=40 / 60$ is obtained which is stronger than that of the self-associated between hydroxyl and carbonyl of the pure PVPh-co-PMMA copolymer $\left(\Delta v=125 \mathrm{~cm}^{-1}\right)$, and this result is consistent with the positive $q$ value obtained in the K wei equation and the observed carbonyl stretching in the infrared spectra.

The $\mathrm{CH}_{2}$ wagging region of the pure $\mathrm{PEO}$ and its blends with PVPh-co-PMMA is now examined. Figure 8 shows infrared spectra in the $1320-1380 \mathrm{~cm}^{-1}$ region of the pure PEO, and various PVPh-co-PMMA/PEO blends. As shown in Figure 8j, the bands at 1360 and $1343 \mathrm{~cm}^{-1}$ represent the crystalline phase of PEO. ${ }^{26}$ These bands decrease slightly as the PVPh-co-PMMA content increases. The crystalline bands disappear at the PVPh-co-PMMA/PEO = 40/60 blend and are re placed by a broad band roughly centered at $1350 \mathrm{~cm}^{-1}$ corresponding to the amorphous phase. The PEO crys- 


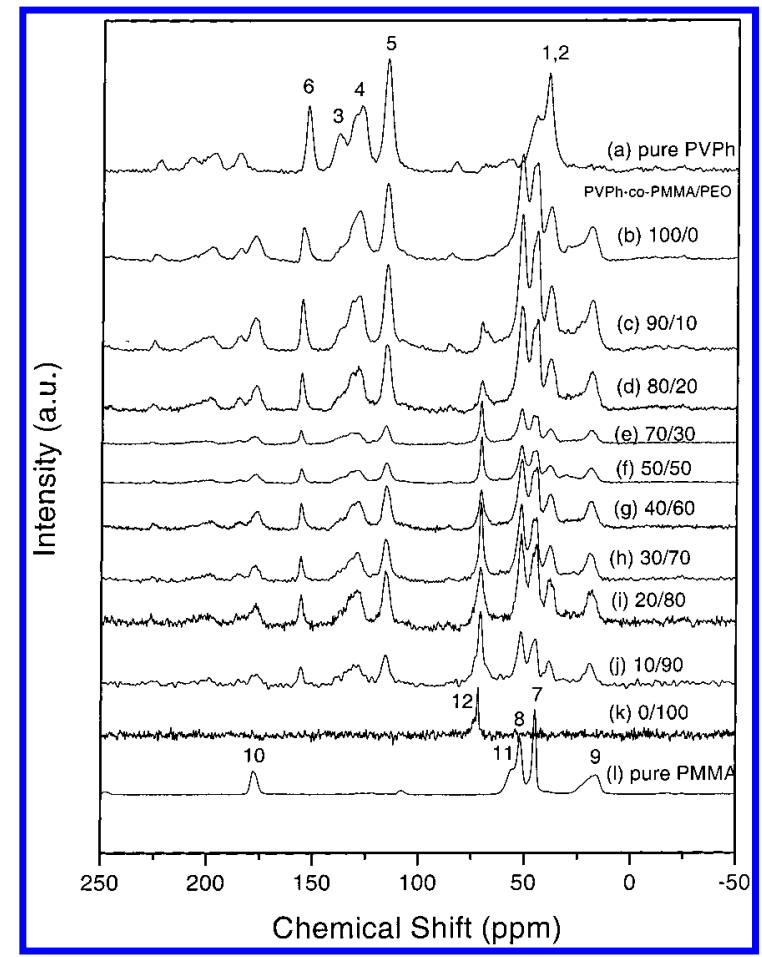

Figure 9. ${ }^{13} \mathrm{C} C \mathrm{CPMAS}$ spectra at room temperature for pure PVPh, pure PMMA and various PVPh-co-PMMA/PEO blends: (a) pure PVPh; (b) 100/0; (c) 90/10; (d) 80/20; (e) 70/30; (f) 50/ 50; (g) 40/60; (h) 30/70; (i) 20/50; (j) 10/90; (k) 0/100; (I) pure PMMA.

Table 4. Chemical Shift of the ${ }^{13} \mathrm{C}$ CP/MAS Spectra of PEO, PVPh, PMMA, and Their Blends

\begin{tabular}{lccc}
\hline \multicolumn{1}{c}{ blend composition } & C-6 & C-10 & C-12 \\
\hline $\begin{array}{l}\text { pure PMMA } \\
\text { pure PVPh }\end{array}$ & 153.24 & 177.00 & \\
$\begin{array}{l}\text { PVPh-co-PMMA/PEO } \\
100 / 0\end{array}$ & 155.61 & 178.33 & \\
$90 / 10$ & 155.76 & 178.18 & 70.72 \\
$80 / 20$ & 156.15 & 178.12 & 70.71 \\
$70 / 30$ & 156.19 & 178.07 & 70.93 \\
$50 / 50$ & 156.20 & 177.11 & 70.79 \\
$40 / 60$ & 156.22 & 177.09 & 70.93 \\
$30 / 70$ & 155.96 & 177.05 & 70.79 \\
$20 / 80$ & 155.79 & 177.00 & 71.02 \\
$10 / 90$ & 155.78 & 176.55 & 70.88 \\
$0 / 100$ & & & 71.76
\end{tabular}

tallization is retarded and even inhibited by adding the amorphous PVPh-Co-PMMA polymer.

Solid State NMR Analyses. Solid-state NMR spectroscopy provides further insight into the phase behavior and morphology of polymer blends involving the hydrogen bond formation. Figure 9 shows the ${ }^{13} \mathrm{C}$ CPMAS spectra of pure PVPh, PMMA, PVPh-co-PMMA, PEO, and PVPh-Co-PMMA/PEO blends of various compositions. The pure PVPh has six resonance peaks and the hydroxyl-substituted carbon in the phenolic ring (C6) is at $153.2 \mathrm{ppm}$. Five peaks can be observed for pure PMMA and the resonance peak at 177.0 ppm is from the carbonyl carbon (C-10). The pure PEO should have two bands corresponding to the methylene carbons (C$12)^{27}$ in the crystalline phase at $72 \mathrm{ppm}$ and the amorphous phase at $70 \mathrm{ppm}$. All other peak assignments are assigned in Figure 9 as shown in Figure 1. Peak positions of these three resonance peaks for the pure components and blends are listed in Table 4. The variation in the observed chemical shift (1.33 ppm) of the carbonyl carbon $(\mathrm{C}=\mathrm{O})$ between the pure PVPh-co-

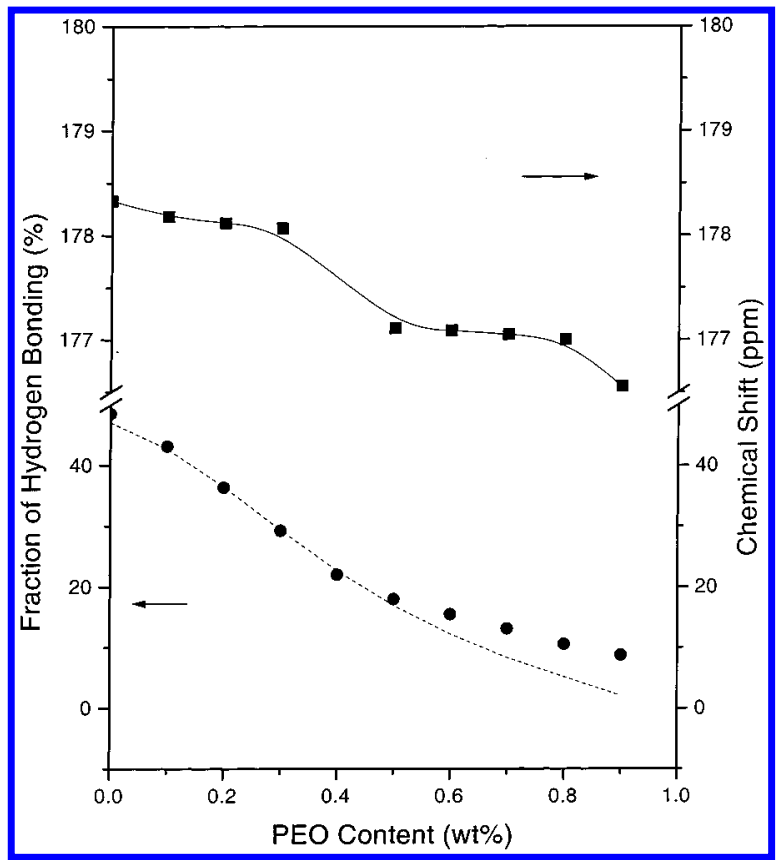

Figure 10. Chemical shift and fraction of hydrogen bonding of carbonyl groups vS PEO content.

PMMA and the pure PMMA indicates the existence of a specific interaction between the PVPh and PMMA segments. It is well-known that the hydrogen bonding in polymer blends can affect the chemical environment of the neighboring molecules, causing a chemical downfield shift. Figure 10 shows the fraction of hydrogen bonding of the carbonyl (Table 2) in FTIR and the corresponding chemical shift in solid state NMR spectra at room temperature vs PEO content. The chemical shift and the fraction of hydrogen bonding of the carbonyl exhibit the same decreasing trend as PEO content increases. Evidently, the strength of the hydroxyl-ether interassociation exceeds that of the hydroxyl-carbonyl self-association. The dashed line is the predicted fraction of hydrogen-bonded carbonyl groups at room temperature according to the Painter-Coleman association model. The theoretical curve accurately predicts the observed hydrogen-bonded carbonyl content at low PEO contents, but deviation increases, due to the intramolecular screening effect ${ }^{28}$ and the presence of a crystalline phase as PEO content in the blend increases.

The hydroxyl-substituted carbon in the phenolic ring (C-6) of pure PVPh-co-PMMA is at $155.61 \mathrm{ppm}$. Compared with the pure PVPh at $153.24 \mathrm{ppm}$, a downfield shift of $2.37 \mathrm{ppm}$ is observed, implying strong intramolecular self-association between PVPh and PMMA segments in the pure PVPh-co-PMMA copolymer. Figure 11 shows the solid-state NMR chemical shift and the FTIR wavenumbers of the hydroxyl group against the PEO content. The chemical shift increases as PEO content increases up to a maximum of 156.25 ppm for the blend containing 60 wt \% PEO and then decreases gradually as the PEO content increases further. The FTIR wavenumber decreases with increasing PEO content and approaches a minimum at $3350 \mathrm{~cm}^{-1}$, also for the blend containing $60 \mathrm{wt} \% \mathrm{PEO}$, and then increases with further increase of the PEO content. It is well-known that a downfield chemical shift (higher chemical shift) in solid-state NMR and the wavenumber shift to lower wavenumber in FTIR both indicate stronger specific interactions between components. There fore, the solid-state NMR and FTIR results show the 


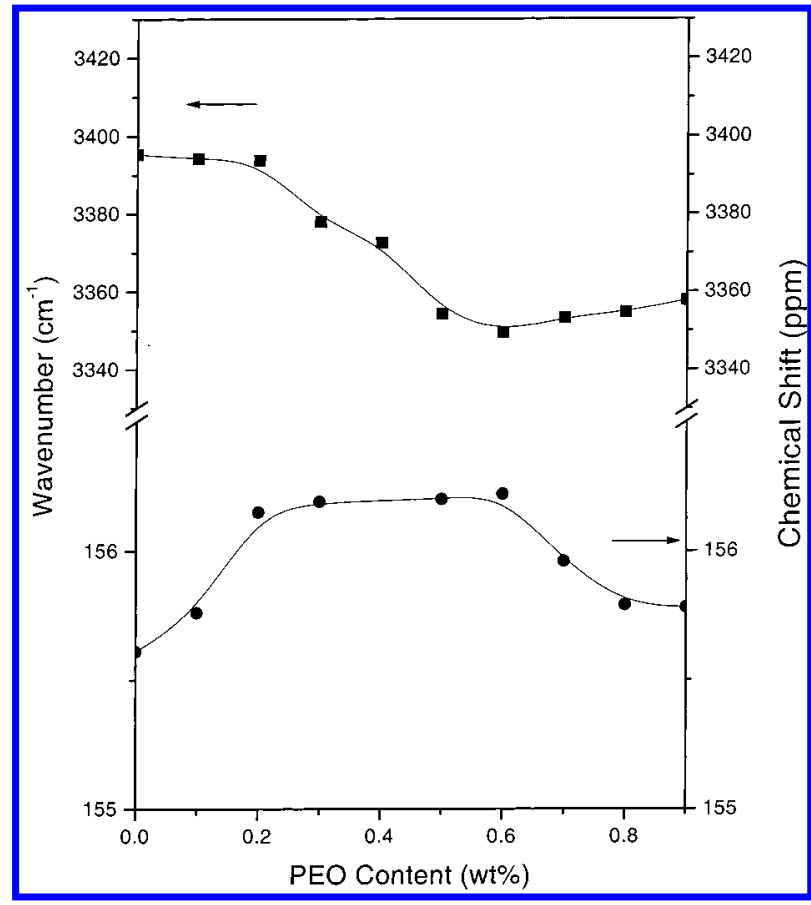

Figure 11. Chemical shift and wavenumber of the hydroxyl groups at room temperature vs PEO content.

same trends over the entire compositions. The lower chemical shift and higher wavenumber at higher PEO content can be explained by the fact that these blend systems possess a crystalline phase. Consequently, the hydroxyl-ether interassociation tends to decrease between the PVPh and PEO segment due to reduced chain mobility in the PEO crystalline phase.

IR spectra for these blends were measured at $150^{\circ} \mathrm{C}$ to support this claim. Measurements carried out at this temperature, above the melting and glass transition temperatures, can eliminate the effect from the PEO crystallization. Therefore, the equilibrium condition is reasonably attained at this temperature. Figure 12 shows the hydroxyl-stretching absorption region of the pure PVPh-co-PMMA and various PVPh-Co-PMMA/PEO blends between 2700 and $4000 \mathrm{~cm}^{-1}$. The wavenumber decreases with increasing PEO content for the entire composition range. This result supports the claim that the previous observed higher wavenumber and lower chemical shift of blends containing higher PEO content (Figure 11) are indeed caused by the presence of the PEO crystalline phase with relatively lower chain mobility. We will discuss the chain mobility by spin lattice relaxation time in the rotating frame using solidstate NMR in the next section.

Proton Spin Lattice Relaxation Time in the R otating F rame Analyses. The spin lattice relaxation time in the rotating frame $\left(\mathrm{T}_{1 \rho}{ }^{\mathrm{H}}\right)$ was measured to examine the homogeneity of PVPh-co-PMMA blends on the mol ecular scale. The magnetization of resonance is expected to decay according to the following exponential function model given by eq 6 , according to the spin locking mode employed in this study, where $\mathrm{T}_{1 \rho}{ }^{\mathrm{H}}$ is the

$$
M_{\tau}=M_{0} \exp \left\lfloor-\tau / T_{1 \rho}(H)\right\rfloor
$$

spin lattice relaxation time in the rotating frame. $\tau$ is the delay time used in the experiment and $M_{\tau}$ is the corresponding resonance. $\mathrm{T}_{1 \rho}{ }^{\mathrm{H}}$ can be obtained from the slope of $\ln \left(\mathrm{M}_{\tau} / \mathrm{M}_{0}\right)$ vs $\tau$,

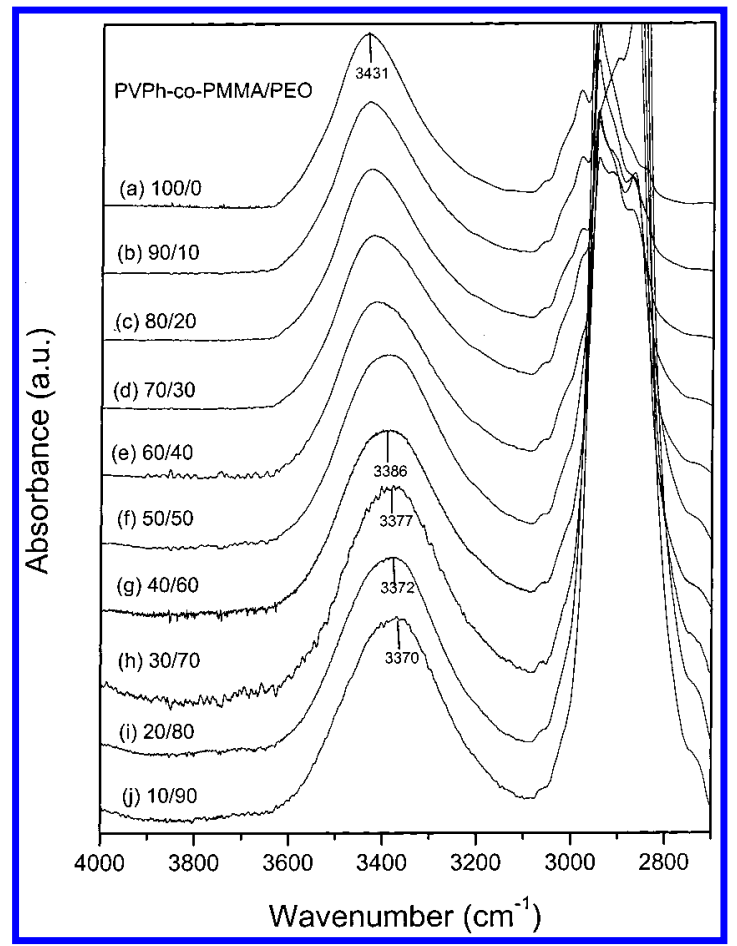

Figure 12. $\mathrm{FTIR}$ spectra recorded at $150{ }^{\circ} \mathrm{C}$ at $2700 \mathrm{~cm}^{-1}$ $4000 \mathrm{~cm}^{-1}$ region for various PVPh-Co-PMMA/PEO blends: (a) 100/0; (b) 90/10; (c) 80/20; (d) 70/30; (e) 60/40; (f) 50/50; (g) 40/ 60; (h) 30/70; (i) 20/50; (j) 10/90.

Table 5. $\mathrm{T}_{1 \rho}{ }^{\mathrm{H}}$ Values of Pure PVPh and Various PVPh-co-PMMA/PEO Blend Compositions

\begin{tabular}{|c|c|c|}
\hline blend composition & 115 ppm & 70 ppm \\
\hline $\begin{array}{l}\text { pure PVPh } \\
\text { PVPh-co-PMMA/PEO }\end{array}$ & 7.24 & \\
\hline $100 / 0$ & 12.08 & \\
\hline $80 / 20$ & 5.12 & 1.48 \\
\hline $40 / 60$ & 4.30 & 1.38 \\
\hline $20 / 80$ & 4.77 & $0.95 \quad 3.93$ \\
\hline $0 / 100$ & & 0.08 \\
\hline
\end{tabular}

Table 5 summarizes those $\mathrm{T}_{1 \rho}{ }^{\mathrm{H}}$ values derived from the binary exponential analysis, indicating that the blend with high PVPh-co-PMMA content exhibits single exponential. However, the biexponential decay gradually appears at higher PEO contents at $70 \mathrm{ppm}$. A semicrystalline polymer will have two proton spin lattice relaxations; the crystalline phase and the amorphous phase, attributed to the long and short relaxation components, respectively. According to Table 5, the amorphous $\mathrm{T}_{1 \rho}{ }^{\mathrm{H}}$ decreases with increasing PEO content in the blend. Meanwhile, a high $\mathrm{T}_{1 \rho}{ }^{\mathrm{H}}$ value for PVPhco-PMMA/PEO $=80 / 20$ blend, implies that the polymer mobility is retarded reflecting the more rigid character of the PVPh-co-PMMA. To the contrary, a decrease of the $\mathrm{T}_{1 \rho}{ }^{\mathrm{H}}$ value in the $\mathrm{PEO}$ rich region is associated with increased mobility of the amorphous PEO, related to the reduction of the intermolecular hydrogen bonding strength. An increasing amount of the long relaxation component with increasing PEO suggests the existence of a more crystalline PEO phase in the blend.

Table 5 also shows that both pure PVPh and PVPhco-PMMA/PEO blends exhibit only single-exponential relaxation throughout all blends at $115 \mathrm{ppm}$, indicating good miscibility and dynamic homogeneity in the PVPhco-PMMA phase. The maximum diffusive path length $\mathrm{L}$ can be estimated using the approximate eq $7 .^{29-31} \mathrm{~F}$ or $\mathrm{T}_{1 \rho}{ }^{\mathrm{H}}$ of $5 \mathrm{~ms}$ and a effective spin diffusion coefficient, 


$$
\mathrm{L}=(6 \mathrm{DT})^{1 / 2}
$$

$D$, of $10^{-16} \mathrm{~m}^{2} \mathrm{~s}^{-1}$, the dimensions of these PVPh-coPMMA/PEO blends are bel ow $2-3 \mathrm{~nm}$ in the amorphous phase. I nterestingly, the $\mathrm{T}_{1 \rho}{ }^{\mathrm{H}}$ has a minimum value for the PVPh-Co-PMMA $=40 / 60$ blend showing that the overall chain mobility is maximal at this composition. This observation agrees with the earlier result concerning hydroxyl group association obtained by FTIR and solid-state NMR. In addition, all blends show shorter $\mathrm{T}_{1 \rho}{ }^{\mathrm{H}}$ than that of the pure PVPh-co-PMMA implying that the PVPh-co-PMMA mobility also increases with the increase of PEO content.

Stoichiometric Equations by Painter-Coleman Association Model. In our previous study, ${ }^{32,33}$ we adopted the Painter-Coleman association model (PCAM) to predict thermodynamic properties. However, all the blends investigated in this study contain a self-associating polymer $B$ and a nonself-associating polymer A, which can interact with $B$. This PCAM model has been modified to account for not only self-association equilibrium in B but several other self-association equilibria, all of which can be studied for the blends in this study. ${ }^{34,35}$ According to the PCAM model, we designate $B, C$, and $A$ as vinylphenol, methyl methacrylate, and ethylene oxide units, respectively, and $K_{2}, K_{B}, K_{C}$, and $\mathrm{K}_{\mathrm{A}}$ as their corresponding association equilibrium constants.

$$
\begin{aligned}
& \mathrm{B}_{1}+\mathrm{B}_{1} \stackrel{\mathrm{K}_{2}}{\longleftrightarrow} \mathrm{B}_{2} \\
& \mathrm{~B}_{\mathrm{h}}+\mathrm{B}_{1} \stackrel{\mathrm{K}_{\mathrm{B}}}{\longleftrightarrow} \mathrm{B}_{\mathrm{h}+1}(\mathrm{~h} \geq 2) \\
& \mathrm{B}_{\mathrm{h}}+\mathrm{C}_{1} \stackrel{\mathrm{K}_{\mathrm{C}}}{\longleftrightarrow} \mathrm{B}_{\mathrm{h}} \mathrm{C} \\
& \mathrm{B}_{\mathrm{h}}+\mathrm{A}_{1} \stackrel{\mathrm{K}_{\mathrm{A}}}{\leftrightarrow} \mathrm{B}_{\mathrm{h}} \mathrm{A}
\end{aligned}
$$

These four equilibrium constants can be expressed as follows in terms of volume fractions

$$
\begin{gathered}
\Phi_{\mathrm{B}}=\Phi_{\mathrm{B} 1} \Gamma_{2}\left[1+\frac{\mathrm{K}_{\mathrm{A}} \Phi_{\mathrm{A} 1}}{\mathrm{r}_{\mathrm{A}}}+\frac{\mathrm{K}_{\mathrm{C}} \Phi_{\mathrm{C} 1}}{\mathrm{r}_{\mathrm{C}}}\right] \\
\Phi_{\mathrm{A}}=\Phi_{\mathrm{A} 1}\left[1+\mathrm{K}_{\mathrm{A}} \Phi_{\mathrm{B} 1} \Gamma_{1}\right] \\
\Phi_{\mathrm{C}}=\Phi_{\mathrm{C} 1}\left[1+\mathrm{K}_{\mathrm{C}} \Phi_{\mathrm{B} 1} \Gamma_{1}\right]
\end{gathered}
$$

where

$$
\begin{aligned}
& \Gamma_{1}=\left(1-\frac{K_{2}}{K_{B}}\right)+\frac{K_{2}}{K_{B}}\left(\frac{1}{\left(1-K_{B} \Phi_{B 1}\right)}\right) \\
& \Gamma_{2}=\left(1-\frac{K_{2}}{K_{B}}\right)+\frac{K_{2}}{K_{B}}\left(\frac{1}{\left(1-K_{B} \Phi_{B 1}\right)^{2}}\right)
\end{aligned}
$$

$\Phi_{\mathrm{B}}, \Phi_{\mathrm{A}}$, and $\Phi_{\mathrm{C}}$ are the vol ume fractions of repeat units in the blend, $\Phi_{\mathrm{B} 1}, \Phi_{\mathrm{A} 1}$, and $\Phi_{\mathrm{C} 1}$ are the volume fractions of isolated units in the blend and $r_{A}=V_{A} / V_{B}$ and $r_{C}=$ $\mathrm{V}_{\mathrm{C}} / \mathrm{V}_{\mathrm{B}}$ are the ratios of segmental molar volumes.

The self-association values of PVPh $\left(K_{2}=21.0\right.$ and $\left.K_{B}=66.8\right)$, the self-association between PVPh and PMMA $\left(K_{C}=67.4\right)$ and interassociation between PVPh and PEO $\left(\mathrm{K}_{\mathrm{A}}=88.3\right)$ were determined by Coleman et al. ${ }^{36,37}$ We did not adopt the interassociation equilibrium $\left(K_{C}=37.5\right)$ between pure PVPh and pure PMMA blend
Table 6. Curve-Fitting Results of PVPh-co-PMMA/PEO = $60 / 40$ Blend at Various Temperatures

\begin{tabular}{rcccccccc}
\hline & \multicolumn{3}{c}{ free $\mathrm{C}=\mathrm{O}$} & & \multicolumn{3}{c}{ H-bonded $\mathrm{C}=\mathrm{O}$} & \\
\cline { 2 - 4 } $\begin{array}{r}\text { temp } \\
\left({ }^{\circ} \mathrm{C}\right)\end{array}$ & $\begin{array}{c}v \\
\left(\mathrm{~cm}^{-1}\right)\end{array}$ & $\begin{array}{c}\mathrm{W}_{1 / 2} \\
\left(\mathrm{~cm}^{-1}\right)\end{array}$ & $\begin{array}{c}\mathrm{A}_{\mathrm{f}} \\
(\%)\end{array}$ & & $\begin{array}{c}v \\
\left(\mathrm{~cm}^{-1}\right)\end{array}$ & $\begin{array}{c}\mathrm{W}_{1 / 2} \\
\left(\mathrm{~cm}^{-1}\right)\end{array}$ & $\begin{array}{c}\mathrm{A}_{\mathrm{b}} \\
(\%)\end{array}$ & $\begin{array}{c}\mathrm{fb} \\
(\%)\end{array}$ \\
\hline 25 & 1728.3 & 18.71 & 74.38 & & 1703.7 & 22.12 & 25.62 & 18.66 \\
50 & 1728.5 & 19.23 & 74.54 & & 1703.0 & 22.46 & 24.46 & 18.54 \\
80 & 1728.8 & 19.33 & 73.56 & & 1703.4 & 23.18 & 26.44 & 19.33 \\
100 & 1728.9 & 19.32 & 72.61 & & 1703.9 & 23.43 & 27.39 & 20.09 \\
120 & 1729.2 & 19.06 & 70.19 & & 1704.8 & 24.15 & 29.81 & 22.06 \\
140 & 1729.4 & 19.32 & 69.34 & & 1705.0 & 23.82 & 30.66 & 22.76 \\
150 & 1729.6 & 19.37 & 68.20 & & 1705.5 & 24.54 & 31.80 & 23.71 \\
160 & 1729.7 & 19.42 & 67.45 & & 1705.8 & 25.02 & 32.55 & 24.33 \\
170 & 1729.7 & 19.56 & 66.93 & & 1706.1 & 25.55 & 33.07 & 24.77
\end{tabular}

derived by Cesteros et al. ${ }^{38}$ due to the composition heterogeneities in the hydrogen bonding polymer system. ${ }^{36}$ Therefore, we used the equilibrium constant previously reported by Coleman et al. for poly(vinylphenol-co-ethyl methacrylate) $\left(K_{C}=67.4\right)$. Table 3 presents the corresponding values of the equilibrium constants and segmental molar volumes. The fraction of hydrogen bonding for a given blend composition can be calculated from eqs 11-13, using

$$
\mathrm{f}_{\mathrm{HB}}=1-\frac{\Phi_{\mathrm{C} 1}}{\Phi_{\mathrm{C}}}
$$

Therefore, the predicted fraction of hydrogen bonding of carbonyl groups (dashed line) in Figure 11 can be calculated numerically.

FTIR Analyses at Various Temperatures. Table 6 summarizes the quantitative analysis of the fraction of the hydrogen bonding carbonyl groups from 25 to $170{ }^{\circ} \mathrm{C}$ for the PVPh-co-PMMA/PEO $=40 / 60$ blend which decreases from 25 to $50{ }^{\circ} \mathrm{C}$, and then increase with further increases of temperature. In general, the $\mathrm{f}_{\mathrm{HB}} \mathrm{C}=\mathrm{O}$ decreases with increasing temperature as would be expected. Initially, this observation seems counterintuitive. However, for a multicomponment hydrogenbonding system containing different competing acceptor groups, different enthalpies from different hydrogen bond formations can markedly affect the equilibrium constant. The same phenomenon is observed in poly(vinyl phenol-co-n-butyl methacrylate) and the styrenestat-2-vi nyl pyri dine blend system observed by Col eman et al. ${ }^{39}$

From the Van't H off relationship shown in eq 18, we

$$
K=-\frac{\Delta h}{R T}+C
$$

can plot the values of the different equilibrium constants as a function temperature from 25 to $200^{\circ} \mathrm{C}$, as shown in Figure 13. Curves $\mathrm{K}_{\mathrm{A}}$ and $\mathrm{K}_{\mathrm{C}}$ represents the competition of the hydroxyl-ether interassociation and hydroxyl-carbonyl self-association, respectively. The equilibrium constants, $\mathrm{K}_{\mathrm{A}}$ and $\mathrm{K}_{\mathrm{C}}$ change with temperature at different rates. It can be found that $\mathrm{K}_{\mathrm{A}}=\mathrm{K}_{\mathrm{C}}$ at about $70^{\circ} \mathrm{C}$. This result implies that the equival ent numbers of the hydroxyl-carbonyl association are favored because $K_{C}$ exceeds $K_{A}$ above $70{ }^{\circ} \mathrm{C}$. Therefore, the observation that the fraction of hydrogen bonded carbonyl groups increases with increasing temperature can be explained by the Painter-Coleman association model.

\section{Conclusions}

PVPh-co-PMMA and PEO are completely miscible in an amorphous phase over the entire composition range. 


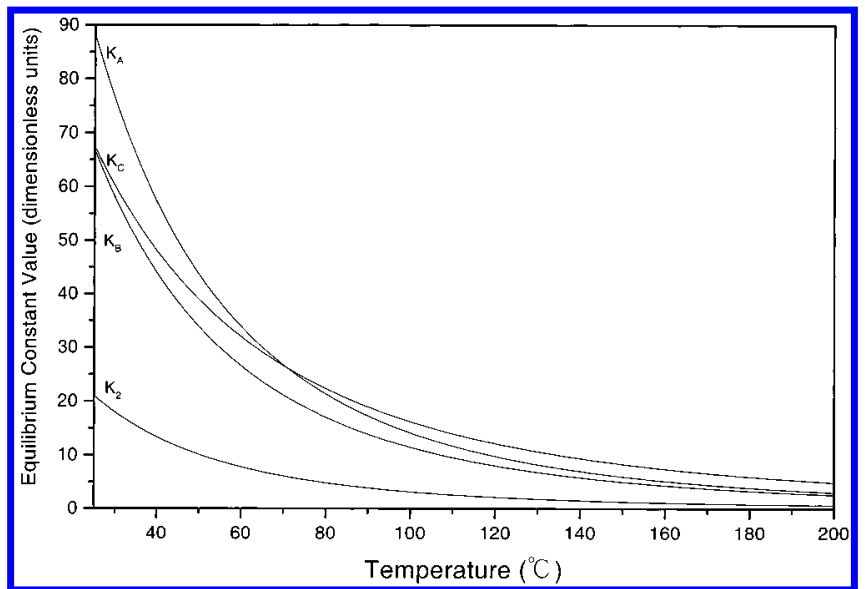

Figure 13. Equilibrium constant values as a function of temperature from 25 to $200{ }^{\circ} \mathrm{C}$.

A negative polymer-polymer interaction energy density $\mathrm{B}$ was calculated from the melting depression of PEO, using the Nishi-Wang equation and the single-exponential decay of proton spin-lattice relaxation times in the rotating frame $\left(\mathrm{T}_{1 \rho}{ }^{\mathrm{H}}\right)$ in amphorous PVPh-co-PMMA phase, as can be observed with solid state NMR. The $\mathrm{K}$ wei equation can accurately predict $\mathrm{T}_{\mathrm{g}} \mathrm{s}$ from experimental results due to the existence of hydrogen bonding between PVPh-co-PMMA and PEO.

Both ${ }^{13} \mathrm{C}$ solid-state NMR and FTIR were employed to study the specific interaction at various compositions and various inter and intramolecular hydrogen bonding. The hydroxyl-ether association dominates at room temperature but the hydroxyl-carbonyl association dominates at higher temperatures $\left(>70{ }^{\circ} \mathrm{C}\right)$. The Painter-Coleman association model (PCAM) is able to predict three interacting functional groups according to our experimental results at various temperatures.

Acknowledgment. This research was financially supported by the National Science Council, Taiwan, Republic of China, under Contract No. NSC-89-2216E-009-005. The authors would like to thank Miss S. Y. Fan for her help with NMR measurements.

\section{References and Notes}

(1) Miyoshi, T.; Takegoshi, K.; Hikichi, K. Polymer 1996, 37, 11.

(2) Chu, P. P.; Wu, H. D. Polymer 2000, 41, 101.

(3) Brus, J .; Dybal, J .; Schmidt, P.; Kratochvil, J .; Baldrain, J. Macromolecules 2000, 33, 6448.

(4) Lezcano, E. G.; Coll, C. S.; Prolongo, M. G. Polymer 1996, 37,3603
(5) Li, D.; Brisson, J . Macromolecules 1996, 29, 868.

(6) Chen, H. L.; Liu, H. H.; Lin, J. S. Macromolecules 2000, 33, 4856.

(7) Sawatari, C.; Kondo, T. Macromolecules 1999, 32, 1949.

(8) Wang, J .; Cheung, M. K.; Mi, Y. Polymer 2001, 42, 2077.

(9) Hill, D. J . T.; Whittaker, A. K.; Wong, K. W. Macromolecules 1999, 32, 5285.

(10) Zhong, Z.; Guo, Qipeng.; Mi, Y. Polymer 1998, 40, 27.

(11) Zhang, X.; Takegoshi, K.; Hikichi, K. Macromolecules 1991, 24, 5756.

(12) Cheung, M. K.; Wang, J .; Zheng, S.; Mi, Y. Polymer 2000, 41,1469

(13) Kesel, C. D.; Lefevre, C.; Nagy, J . B.; David, C. Polvmer 1999, 40, 1969.

(14) Etxeberria, A.; Guezala, S.; I ruin, J . J .; Campa, J . G.; Abajo, J. D. Polymer 1998, 39, 1035.

(15) Mekhilef, N.; Hadjiandreou, P. Polymer 1995, 36, 2165.

(16) Qin, C.; Pires, A. T. N.; Belfiore, L. A. Macromolecules 1991, 24, 666.

(17) Coleman, M. M.; Yang, X.; Painter, P. C.; Graf, J . F. Macromolecules 1992, 25, 4414.

(18) Coleman, M. M.; Graf, J . F.; Painter, P. C. Specific Interactions and the Miscibility of Polymer Blends; Technomic Publishing: Lancaster, PA, 1991.

(19) Fox T. G. L. Appl. Bull. Am. Phys. Soc. 1956, 1, 123.

(20) Gordon, M.; Taylor, J. S. L. Appl. Chem. 1952, 2, 493.

(21) Kwei, T. L. Polym. Sci.: Polym. Lett. Ed. 1984, 22, 307.

(22) Nishi, T.; Wang, T. T. Macromolecules 1975, 8, 909.

(23) Flory, P. J . Principles of Polymer Chemistry; Cornell University Press: Ithaca, NY, 1953.

(24) Hoffman, J . D.; Weeks, J J J . L. Chem. Phys. 1965, 42, 4301.

(25) J o, W. H.; Lee, S. C. Macromolecules 1990, 23, 2261.

(26) Chintapalli, S.; Frech, R. Macromolecules 1996, $29,3499$.

(27) Schilling, F. C.; Tonelli, A. E.; Cholli, A. L. L. Polym. Sci. Polym.; Phys. Ed. 1992, 30, 91.

(28) Painter, P. C.; Veytsman, B.; Kumar, S.; Graf, J . F .; Xu, Y.; Coleman, M. M. Macromolecules 1997, 30, 932.

(29) McBrierty, V. J .; Douglass, D. C. L. Polym. Sci., Macromol. Rev. 1981, 16, 295.

(30) Demco, D. E.; J ohansson, A.; Tegenfeldt, J . Solid StateNud. Magn. Reson. 1995, 4, 13.

(31) Clauss, J.; Schmidt-Rohr, K, W. H. Acta Polym. 1993, 44, 1.

(32) Kuo, S. W.; Chang, F. C. Maunuscript submitted for publication.

(33) Wu, H. D.; Chu, P. P.; Ma, C. C. M.; Chang, F. C. Macromolecules 1999, 32, 3097.

(34) Menestrel, C. L.; Bhagwagar, D. E.; Painter, P. C.; Coleman, M. M.; Graf, J . F. Macromolecules 1992, 25, 7101.

(35) Cesteros, L. C.; I sasi, J . R.; Katime, I. Macromolecules 1993, 26, 7256

(36) Coleman, M. M.; Xu, Y.; Painter, P. C. Macromolecules 1994, 27, 127.

(37) Serman, C. J .; Xu, Y.; Painter, P. C.; Coleman, M. M. Polymer 1991, 32, 516

(38) Serman, C. J .; Painter, P. C.; Coleman, M. M. Polymer 1991, $32,1049$.

(39) Coleman, M. M.; Narvett, L. A.; Painter, P. C. Polymer 1998, 39, 5867.

MA010047K 